\title{
(POSTER) Combining Design and Entrepreneurial Mindset Development: Motorcycle Detection System
}

Pilar Echeverria

echeverriator@uindy.edu

Thomas LeSeure

leseuret@uindy.edu

Bailey Wilder

wilderb@uindy.edu

Oluebubechukwu Onaga

onagao@uindy.edu

Jake Braumbaugh

braumbaughj@uindy.edu

See next page for additional authors

Follow this and additional works at: https://docs.lib.purdue.edu/aseeil-insectionconference

Part of the Engineering Commons

Echeverria, Pilar; LeSeure, Thomas; Wilder, Bailey; Onaga, Oluebubechukwu; Braumbaugh, Jake; Spicklemire, Steve Dr.; Sanchez, Jose Dr.; and Olawale, David Dr., "(POSTER) Combining Design and Entrepreneurial Mindset Development: Motorcycle Detection System" (2019). ASEE IL-IN Section Conference. 7.

https://docs.lib.purdue.edu/aseeil-insectionconference/2019/posters/7 
Presenter Information

Pilar Echeverria, Thomas LeSeure, Bailey Wilder, Oluebubechukwu Onaga, Jake Braumbaugh, Steve Spicklemire Dr., Jose Sanchez Dr., and David Olawale Dr. 


\section{Combining Design and Entrepreneurial Mindset Development: Motorcycle}

\section{UNIVERS ITY of}

I N D I A N APOLIS

R.B. Annis School of Engineering

\section{Detection System}

By: Jake Braumbaugh, Pilar Echeverria,TJ LeSeure, Ebube Onaga, Bailey Wilder

EAGLE EYE

Faculty Advisors: Dr. Jose Sánches, Dr. Steve Spicklemire, Dr. David Olawale, Dr. Rashedul Sarker, Mr. James Emery

\section{Introduction}

\section{Introduction}

Motorcycles splitting lanes can be common problem in populated cities, especially outside the United States. A team of five engineers (team SPOT) identified a need for a system which can easily detect motorcycles driving between lanes on the road. The development of such product (Eagle Eye) will improve safety and quality of life for both purchasers and motorcyclist.

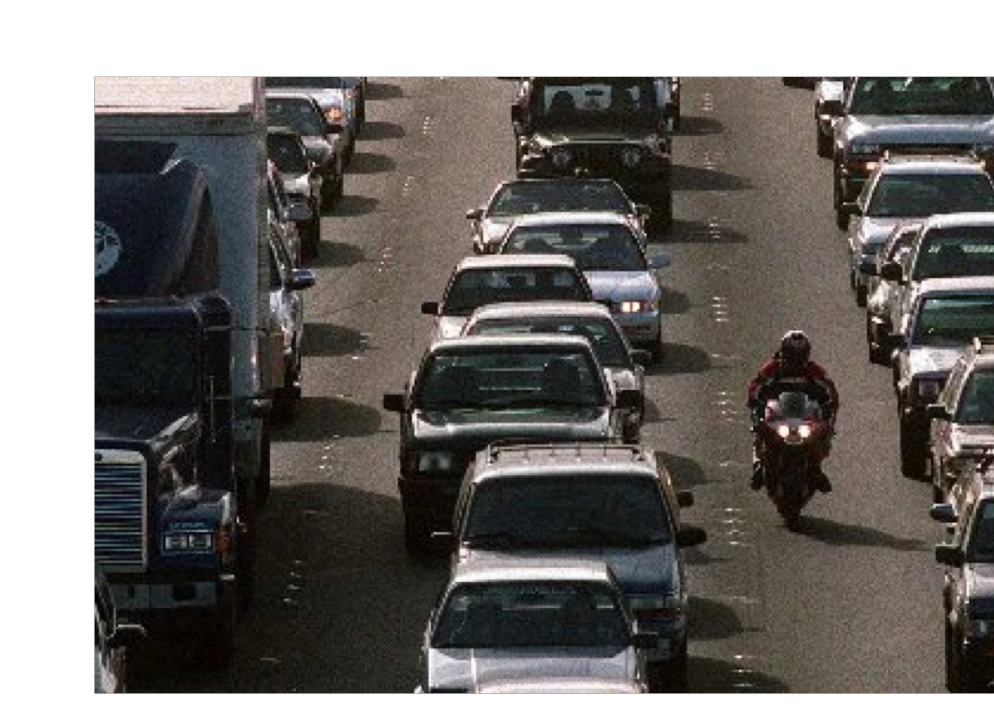

Figure I: Motorcycle Cutting Lanes

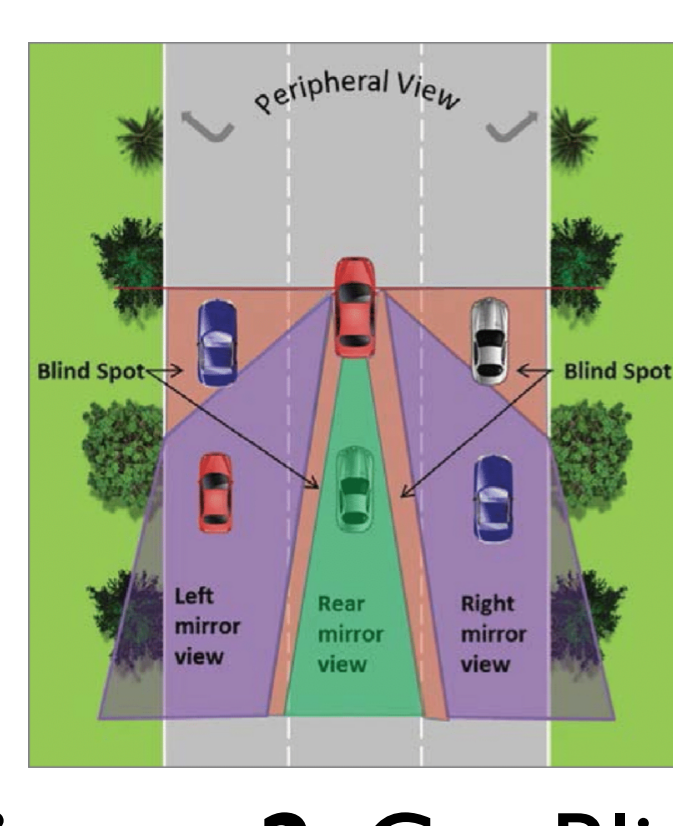

Figure 2: Car Blind Spots

\section{Objective}

Improve road safety for both direct and indirect users.

\section{Motivation}

There is a dire need internationally for a product that detects motorcycles splitting lanes. Team members are passionate about the benefits that a product like Eagle Eye will bring to developing countries.

\section{Significance}

By creating a cheap and self-mountable product for vehicles that detects motorcycles cutting though lanes, road safety would be improved.

\section{Methods}

Team SPOT combined entrepreneurial techniques to come up with a solution to a current problem. The different steps [Fig. 2] were crucial to the development and improvement of Eagle Eye.

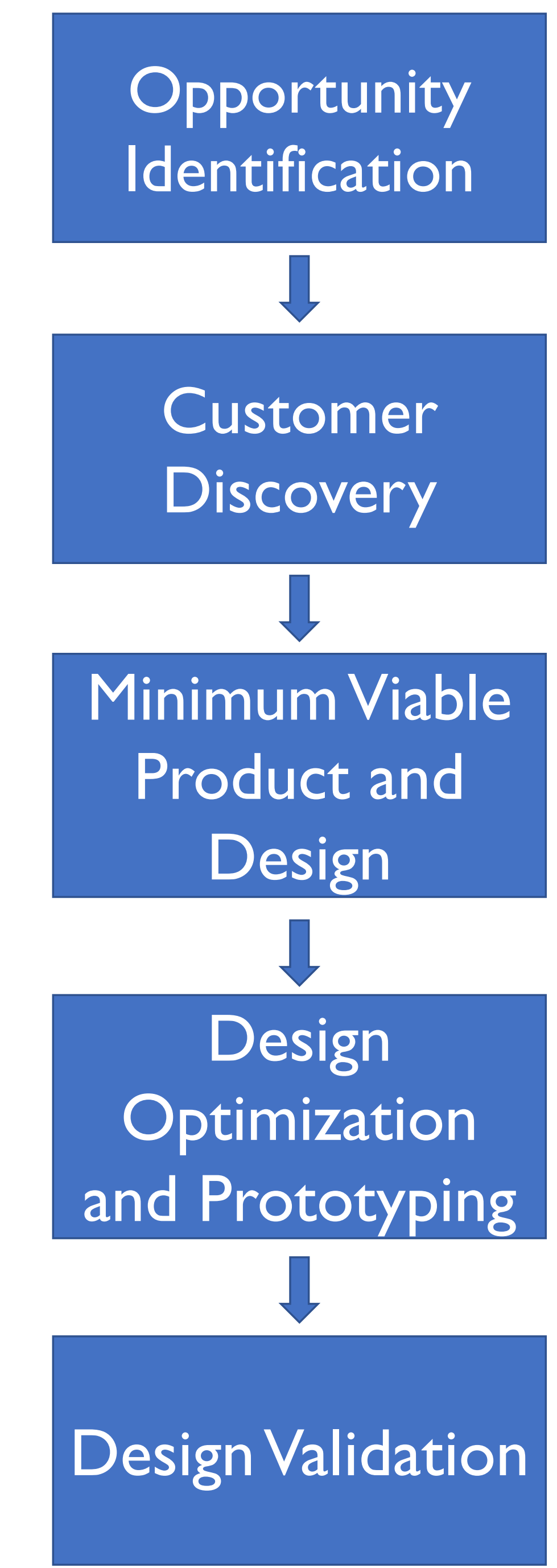

Figure 3: Steps Taken by SPOT

\section{Main Insights:}

- Potential customers from $30+$ countries think it is a good idea and are willing to buy

Focus on:

- ClearWarnings

- Range of System Vision

- Weight of Product

- Waterproof

- Where to separate from competition:

- Low Cost $(>\$ 120)$

- Self Mountable

- Solar Power

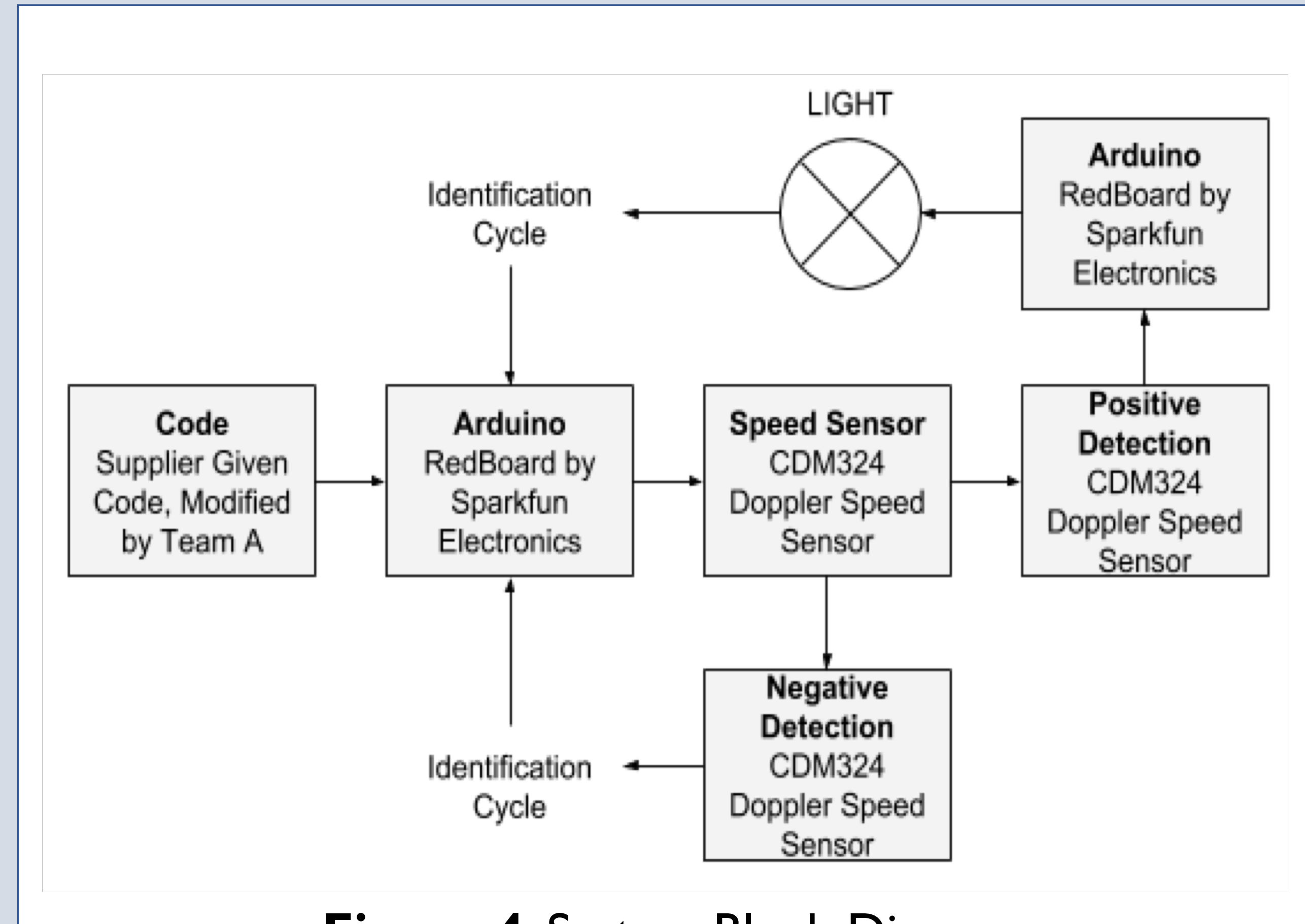

Figure 4: System Block Diagram

Components
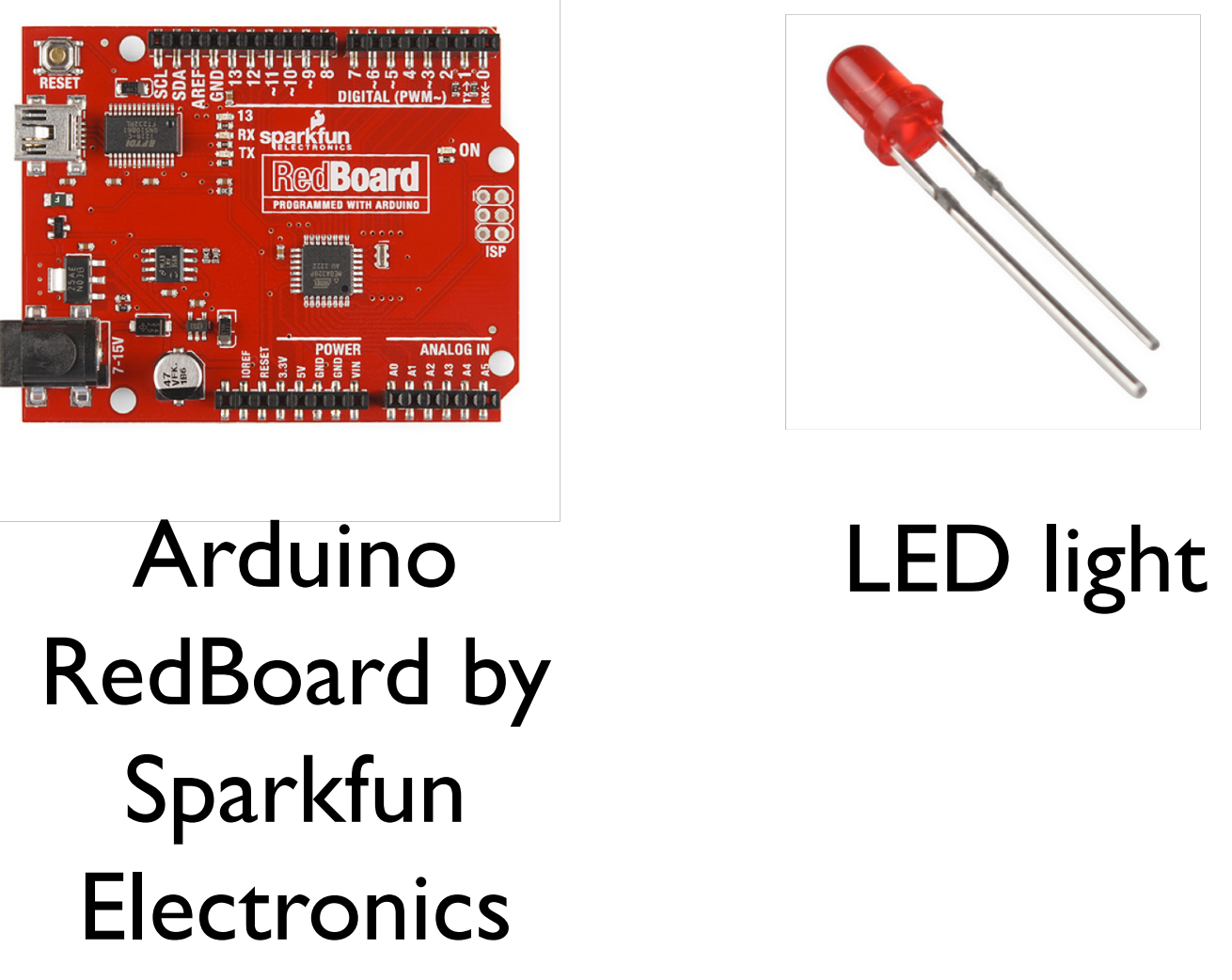

LED light Electronics

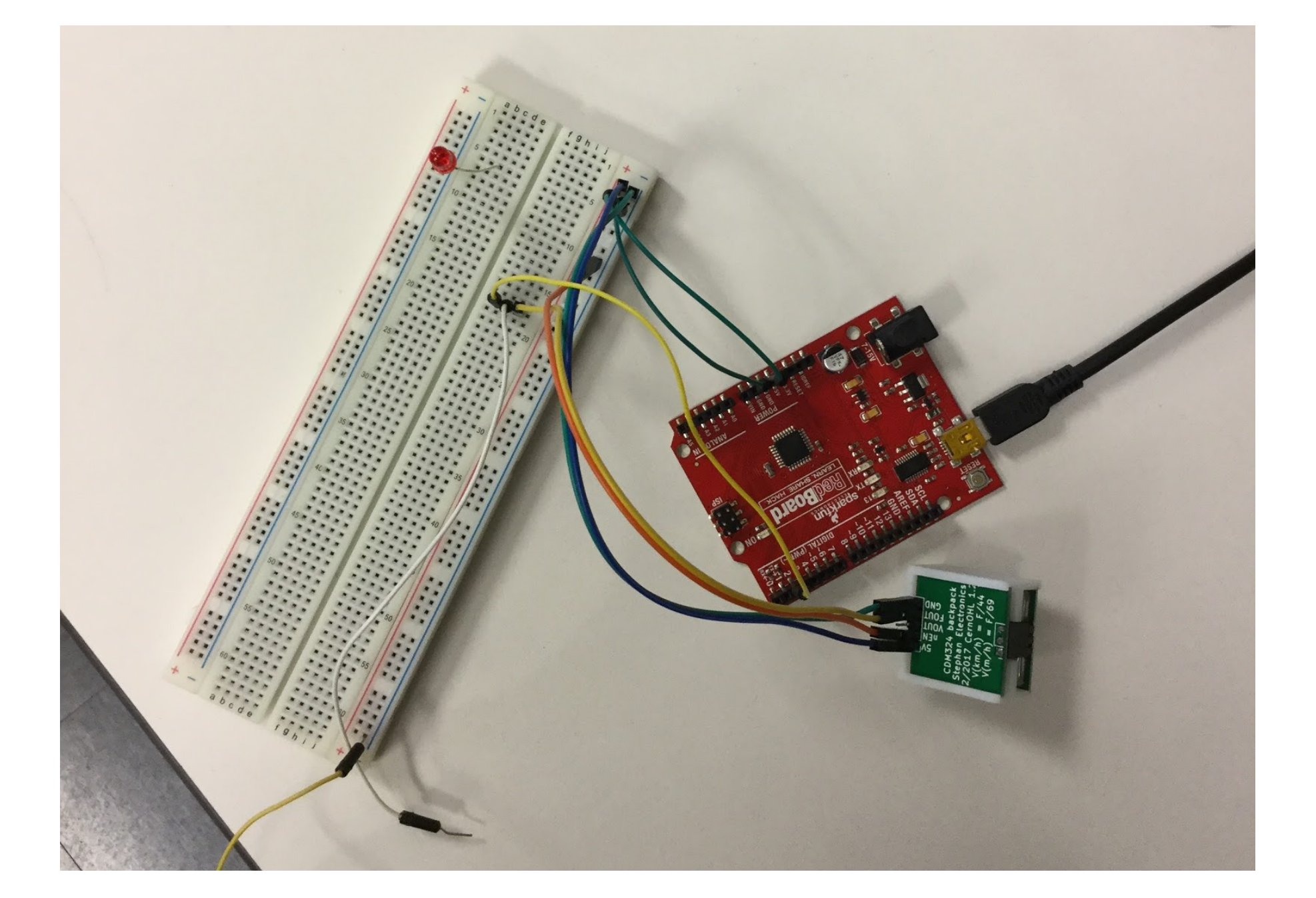

Figure 5: Code and Sensor Testing Set

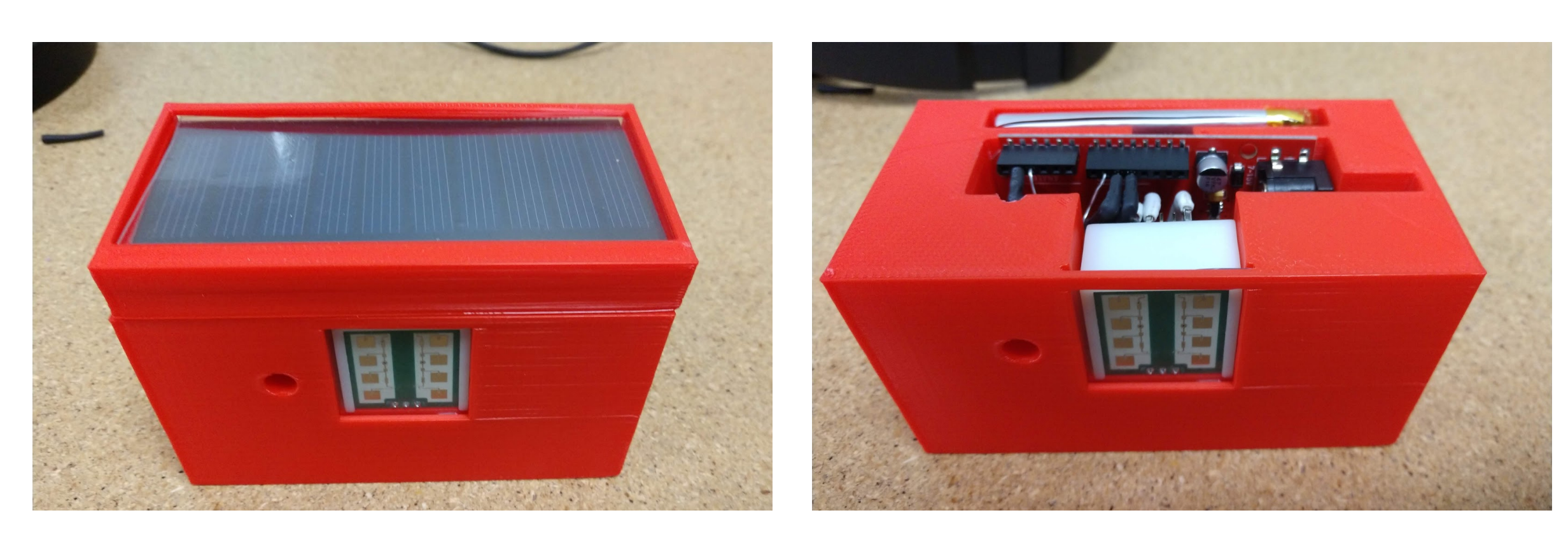

Figure 5: Prototype

\section{Results}

\section{Testing}

For Eagle Eye to be a successful product, it is crucial that a reliable and timely warning is given. Meticulous tests on the coding and speed sensor were done to identify the range of noise data. Those values were filtered with coding.

\section{Conclusion}

\section{Conclusion}

Team SPOT developed a product based on the need to provide low-cost, selfmountable, and solar-powered motorcycle detection system to help reduce crashes resulting from motorcycle lane splitting. As the testing phase continues, the next steps are to do field testing, explore mounting options and a potential on/off button.

\section{Acknowledgements}

Special thanks to our business mentors Mrs. Terry Moore and Dr. David Olawale; and to the faculty of the R.B. Annis School of Engineering for the constant support and guidance. Last but not least, to the team of designers that gave a face to our product.

\section{References}

\section{[I] Motorcycle Cutting Lanes: https://www.wired.com/2015/06/yes-} california-let-motorcycles-ride-cars/ [2] Car Blind Spots: https://www.researchgate.net/figure/Blind-spotaround-a-vehicle ffig2_319851766 vs-unolall [4] CDM324 Doppler Speed Sensor: https://www.tindie.com/products/stephanelec/cdm324-doppler-speed[5] LED light: hetps://www.dx.com/p/diy-3mm-led-light-emitting. 